\title{
Resorting to Internet: A look at university students' problematic Internet use through meaning in life, self- efficacy and self-esteem ${ }^{1}$
}

\author{
Betül Aydın
}

\begin{abstract}
Internet can be used in a maladaptive way to escape from or compensate perceived inadequacies or the problems experiencing in daily life. In relation to this, in this study the relationship of meaning in life, self-efficacy and self-esteem to problematic Internet use was examined. Furthermore, the role of meaning in life, self-efficacy and self-esteem in predicting problematic Internet use was investigated. The study was carried out 410 university students $(280$ females and 130 males) attending the different grades of various departments in a school of education in Rize, Turkey. In the study, Sociodemographic Data Form, Problematic Internet Use Scale, Meaning in Life Questionnaire, General Self-Efficacy Scale and Rosenberg Self-Esteem Scale were used as data collection instruments. The data were analyzed through SPSS 15.0 version and descriptive statistics, Pearson product-moment correlation coefficient and multiple linear regression analysis were utilized in the analysis. Results showed that presence of meaning in life ( $\mathrm{r}=-.26, \mathrm{p}<.01)$, selfefficacy $(\mathrm{r}=-.36, \mathrm{p}<.01)$ and self-esteem $(\mathrm{r}=-.30, \mathrm{p}<.01)$ are negatively and significantly correlated to problematic Internet use, on the contrary, search for meaning's relationship was found in a positive way $(\mathrm{r}=.21, \mathrm{p}<.01)$. Besides, presence of meaning in life, search for meaning in life and self-efficacy emerged as significant predictors of problematic Internet use. By discussing these results in line with the relevant literature, directions were given for further studies.
\end{abstract}

Keywords: Meaning in life; problematic internet use; self-efficacy; self-esteem; university students.

\section{Introduction}

Technology, Internet use in particular, is an almost integral part of the daily life. People consider Internet as an indispensable means for education, health, socializing, personal development, having a nice time, communicating, and national and global awareness (Internet Society, 2012). Despite the fact that it facilitates and colors humans' life, researches signify that the relationship between Internet and human can be "disordered". Young (1996) reported this disordered relationship between human and Internet as a pathological situation called as "Internet addiction" for the first time, in a study conducted by 600 Internet users. Today, 20 years after it was firstly reported that it can be used in a way cause overuse and addiction, around 3.4 billion people access Internet in the world (Internet Live Stats, 2016). Mobile data, wireless networks, mobile devices such as smart phone and tablets, social networking sites mobile applications with features changing almost every day have rendered Internet more accessible and attractive. Internet related concepts such as "selfie", "snap", "stalking", "check-in", "tweet", "instant messaging", "re-post" are

\footnotetext{
1 This study was presented as oral presentation in $10^{\text {th }}$ International Computer \& Instructional Technologies Symposium which took place on May 16 ${ }^{\text {th }}-18^{\text {th }} 2016$ at Recep Tayyip Erdoğan University in Rize , Turkey

2 Asst. Prof. Dr., Recep Tayyip Erdoğan University, Faculty of Education, Department of Psychological Counseling and Guidance, betul.aydin@erdogan.edu.tr
} 
Aydın, B. (2017). Resorting to Internet: A look at university students' problematic Internet use through meaning in life, self-efficacy and self-esteem. Journal of Human Sciences, 14(2), 1938-1950. doi:10.14687/jhs.v14i2.4480

now commonly used in the daily language in many nations. Penetration of Internet into people's life this much draws attention to concept of problematic Internet use.

The overuse of Internet which may cause adverse results is conceptualized in literature as "Internet addiction", "Internet addiction disorder", "compulsive Internet use", "Internet overuse", "pathological Internet use", and "problematic Internet use". Since such concepts bear the same meaning to some extent (Widyanto \& Griffits, 2006), they were preferred in the article interchangeably. The need to have more time on Internet, anxiety when the person is not online, agitation and obsessive thoughts when not online, the extreme need to go online, interruption of the person's daily activities, occupational, educational, financial and family related problems caused by Internet use signify problematic use of Internet (Goldberg, 1996; Young, Yue \& Ying, 2011). Problematic Internet use is observed in different cultures (Huang, Lu, Liu, You, Pan, Wei et al., 2009; Johansson \& Götestam, 2004; Liu, Desai, Krishnan-Sarin, Cavallo \& Potenza, 2011; Şenormanc1, Konkan, Güçlü \& Şenormanc1, 2014) and its prevalence changes by age groups. The prevalence rates of problematic Internet use are estimated to be approximately between $4 \%$ to $18 \%$, with the highest incidence among university students (Aboujaoude, Koran, Gamel, Lorge \& Serpe, 2006; Cao, Sun, Wan, Hao \& Tao, 2011; Huong et al., 2009; Niemz, Griffiths \& Banyard, 2005). University students are considered under risk with regards to problematic Internet use due to psychological and developmental characteristics related to late adolescence/early adulthood, easy access to Internet and others' expectations from them on using computer/Internet in academic duties (Kandell, 1998; Young, 2004). Researches orienting on the determinants of the problematic Internet use have mainly focused on the psychosocial characteristics of individuals related to the problematic Internet use. Based on the results of this research; social isolation and loneliness (Hardie \&Tee, 2007; Huan, Ang, Chong \& Chye, 2014), self-related problems (Kim \& Davis, 2009; Smahel, Blinka \& Ledabyl, 2008), alcohol and drug addiction (Ko, Yen, Chen, Chen, Wu \& Yen, 2006; Yen, Ko, Yen, Chen \& Chen, 2009), and depressive tendencies (Whang, Lee \& Chang, 2003; Young \& Rogers, 1998) are common characteristics of overusers. Individuals suffering from psychosocial problems seem to be under risk for Internet overuse.

\section{1.Meaning in life and problematic Internet use}

The overuse of the Internet with the purpose of escaping from the facts of life suggests us the question whether the individuals overusing the Internet are people experiencing problems with the course, purpose, and importance of life and compensating this perceived inadequacy in a maladaptive way by means of Internet overuse. And this question establishes an association between the problematic use of Internet and meaning in life. Meaning in life, which is defined as people's attribution importance to their life in line with their aim, mission, and presence of a comprehensive goal in their lives, consists of two dimensions separated from each other theorically: presence of meaning and search for meaning. While presence of meaning expresses the degree of perception of life as important, predictable, understandable, purpose-oriented and mission-laden, search for meaning corresponds to the efforst of the individual to configure or strengthen the relevant importance, purpose, and mission (Steger, Kashdan, Sullivan \& Lorentz, 2008: 200). Those feeling inadequacies in meaning of his life search for more meaning, but others finding their lives meaningful rarely or never search for meaning (Steger, Fraizer, Oishi \& Kaler, 2006). Perceived meaning in life was found to be positively correlated to many psychological well-being and physical health indicators (Reopke, Jayawickreme \& Riffle, 2014; Steger, Fitch-Martin, Donnelly \& Rickard, 2015). On the other hand, the more search for meaning in life increases (Steger, Mann, Michels \& Cooper, 2009) the more anxiety, depression level and health risking behaviors increase (Marco et al., 2015), and level of psychological and pysical well being decreases (Steger et al., 2006; Steger et al., 2009). Meaning in life reported by individuals addicted to smoking, substance, alcohol, and drugs is found to be lower compared to those not addicted to such (Nicholson et al., 1994; Thege, Urban \& Kopp, 2013; Waisberg \& Porter, 1994) and meaning in life plays a facilitating role in psychotherapy (Debats, 1996). Furthermore, positive relationship between the Internet addiction 
Aydın, B. (2017). Resorting to Internet: A look at university students' problematic Internet use through meaning in life, self-efficacy and self-esteem. Journal of Human Sciences, 14(2), 1938-1950. doi:10.14687/jhs.v14i2.4480

and stressful life events (Whang et al., 2003), family problems (Lam, Peng, Mai \& Jing, 2009), psychological traumas (Dalbudak, Evren, Aldemir \& Evren, 2014), and academic problems (Iskender \& Akın, 2010; Odac1, 2011) gives the idea that problematic Internet use can be considered as a problem of meaning in life.

\section{2. Self-efficacy and problematic Internet use}

Problematic Internet use is considered as a result of the psychological mechanisms which has been functioning for long in individual (Armstrong, Phillips \& Saling, 2000; Kardefelt-Winther, 2014a). One of these psychological mechanisms is the beliefs of the person about the world and himself and these beliefs are the main determinants of the dysfunctional behaviors related to the overuse of the Internet (Davis, 2001). Self-efficacy which is the main concept of the Social Cognitive Theory based on the assumption that people try to have control over the important events which could affect their lives through their beliefs and actions, is defined as the belief of the person in his own capacity to achieve the desired outputs (Bandura, 1999a: 1-2). Self-efficacy belief is generally considered to be domain-specific. Furthermore, it is reported that individual's previous experiences on accomplishment or failure create an expection that they will affect the type of behaviour in new situations and this general exception is conceptualized as "general self-efficacy belief" (Sherer, Maddux, Mercandante, Dunn, Jacobs et al., 1982). In a cross-cultural study (Luszczynska, Gutierrez-Dona \& Schwarzer, 2005), general self-efficacy was found to be positively correlated to life satisfaction, work satisfaction, academic success, relationship quality, and positive affect while negatively correlated to depression and anxiety. Additionally, it is reported that individuals with low self-efficacy are more vulnerable to addictions (Marlatt, Baer \& Quigley, 1999). Young et al. (2011: 12) similarly state that one of the characteristics of the individuals inclined to Internet addiction is that they make efforts to overcome the inadequacy perceived in real life through specific Internet applications. Inadequacies experienced in daily life and related to stressful social, academic, occupational or home-family life may direct people to using Internet with the purpose of compensating this perceived inadequacy or accomplishing the thing perceived to be inadequate (Caplan \& High, 2011; Kardefelt-Winther, 2014a; Kardefelt-Winther, 2014b). Beliefs such as "I am more effective on Internet", "I have more self-confidence on Internet", and "I feel more comfortable on Internet" related to the use of social networks, game, entertainment, frienship and flirting sites (Davis, 2001) may cause the need to have more time online and the mood can be regulated in this way (Caplan \& High, 2011). Also, the likelihood that the perceived low self-efficacy prevents keeping the use of Internet under control demonstrates a stronger connection between the self-efficacy and problematic Internet use.

\subsection{Self-esteem and problematic Internet use}

Self-esteem is defined as the general attitude of the person towards himself/herself (Rosenberg, Schooler, Schoenbach \& Rosenberg, 1995:141) and considered for long years as a variable supporting the mental health, adaptive and effective behaviors in the social, academic, occupational, and daily life (Dumont \& Provost, 1999; Judge \& Bono, 2001; Paradise \& Kernis, 2002). Low self-esteem, on the other hand, is found to be correlated to depression and anxiety (Sowislo \& Orth, 2013), and offensive, aggressive and anti-social behaviors (Donnellan, Trzesniewski, Robins, Moffitt \& Caspi, 2005). Furthermore, research findings show that the individuals suffering from low self-esteem look to drug use (Peterson, Buser \& Westburg, 2010), compulsive shopping (Hanley \& Wilhelm, 1992), and gambling (Volberg, Reitzes \& Boles, 1997) to feel better. The recent studies also signify that Internet can be preferred by people as a means of creating a different identity, presenting himself/herself others freely as "how he/she wants to be", so that they can have better feelings for themselves. For example, Mehdizadeh (2010) reports that the Facebook users with low self-esteem use Facebook mainly for self-promoting and they are online longer hours compared to users with high level of self-esteem. Another study showed that the likes the users took for their shares on social networking sites allow them to feel better about 
Aydin, B. (2017). Resorting to Internet: A look at university students' problematic Internet use through meaning in life, self-efficacy and self-esteem. Journal of Human Sciences, 14(2), 1938-1950. doi:10.14687/jhs.v14i2.4480

themselves (Valkenburg, Peter \& Schouten, 2006). The fact that $90 \%$ of the Internet users use a social networking site (Internet Society, 2012) and the positive feedback made by others strengthens the self-esteem (Hewitt, 2002) renders the relationship between the self-esteem and Internet use worhty of attention. It is no wrong to say that, with regards to self-esteem, similar situations apply to the gaming sites commonly used by Internet users. For example, Li et al. (2011) reports that the adolescents, who have discrepancies between the real self and ideal self, play massively multiplayer online role playing games (MMORPG) as a way to escape from depression based on this problem. Because feeling better through specific Internet sites and applications may cause the duration spent on such sites to increase and the need to enter these sites more frequently, risk of problematic use is considered to be higher.

\section{Purpose}

The purpose of this study is to investigate the relationship of problematic Internet use with meaning in life, general self-efficacy, and self-esteem and to determine the roles of meaning in life, self-efficacy, and self-esteem in predicting the problematic Internet use. In this context, it is considered that the present study will expand the literature focusing on the role of psychosocial problems on over and unhealthy Internet use by means of tackling the self-esteem, also meaning in life and general self-efficacy variables which were not handled previously as far as is known. On the other hand, the research was carried out in Turkey which is one of the top 20 countries for Internet use rates (Internet World Stats, 2015) with university students considered to be a group under risk for problematic Internet use (Kandell, 1998; Young, 2004) and therefore it is thought that the research would contribute to the literature significantly.

Based on the examination of the relevant literature, following hypotheses were established:

H1 Search for meaning in life is positively and significantly correlated to the problematic Internet use.

H2 Presence of meaning in life is negatively and significantly correlated to the problematic Internet use.

H3 Self-efficacy is negatively and significantly correlated to the problematic Internet use.

H4 Self-esteem is negatively and significantly correlated to the problematic Internet use.

H5 Search for meaning in life, presence of meaning in life, self-efficacy and self-esteem are significant predictors of problematic Internet use.

\section{Method and material}

\section{1. Participants}

The research was carried out with 410 students randomly sampled studying in the Primary School Teaching, Social Sciences Teaching, Science Teaching, Turkish Language Teaching, Computer and Instructional Technologies Teaching and Psychological Counseling and Guidance programs of Faculty of Education in Recep Tayyip Erdoğan University based in Rize-Çayeli during the spring term of 2015-2016 academic year. Distribution of participants by gender is $280(68.3 \%)$ females and $130(37.1 \%)$ males. Average age of the sample is $21.7(\mathrm{SD}=1.86)$ and majority of participants $(87.6 \%)$ are coming from middle-income families.

$74.1 \%$ of the participants have a computer. Also, they substantially $(87.1 \%)$ go online via their mobile phones. $57.3 \%$ of the students use Internet mainly for social media access, $35.4 \%$ use for surfing, $6.1 \%$ use for homework and $1.2 \%$ for e-mail. For daily Internet use durations, majority of the participants (65.8\%) use Internet around 2-4 hours. Furthermore, 19.2\% spend 1 hour or less, while $15 \%$ spend 5 hours or more on Internet daily. 
Aydın, B. (2017). Resorting to Internet: A look at university students' problematic Internet use through meaning in life, self-efficacy and self-esteem. Journal of Human Sciences, 14(2), 1938-1950. doi:10.14687/jhs.v14i2.4480

\section{2. Procedure and research ethics}

Relevant permissions required to collect data were obtained from the faculty deanship. Data collection tools were applied to the students within course hours during two weeks with the permission of the relevant lecturers. Before application, participants were informed of the purpose of the research and of that the participation was on voluntariry basis. The students being voluntary on participating were presented with a data collection pack consisting of Sociodemographic Information Form, Problematic Internet Usage Scale, Meaning in Life Scale, General Self-efficacy Scale, and Rosenberg Self-Esteem Scale. The data collection process carried out in accordance with The Code of Ethics of the World Medical Association (Declaration of Helsinki, 2013) and all the students gave their informed consent in participating the study. Students answered all items within around 30 minutes. Data collection was performed by the researcher. During the data entry, 55 data collection packs with missing parts in answers were eliminated from the evaluation and analysis was based on the data of 410 students.

\section{3. Data collection tools}

\section{3. 1. Sociodemographic data form}

This form was prepared by the researcher. The form included questions on gender, department, age, perceived socioeconomic status, possession of a computer or not, daily Internet use time, generally preferred means of connecting Internet, and the most common purposes of going online.

\subsubsection{Problematic Internet usage scale}

This scale was developed by Ceyhan, Ceyhan and Gürcan (2007) to determine the problematic Internet use of university students. The scale consists of 33 items the 31 of which is positive (e.g. "Whenever I decide to unconnect my Internet access, I say myself "a few minutes more".) and 2 is negative-reverse coding (e.g. "Unless it is necessary, I avoid using Internet") and has 5-point likert type. This 33 items includes three factors as "adverse outputs of Internet", "social benefit/social comfort", and "overuse" which explain the $48.96 \%$ of the total variance. The correlation of the scale with Turkish version of Online Cognition Scale was calculated as .61. Internal consistency coefficient was found to be .94 . Increasing points obtained from the scale indicates the increase of level of the problematic Internet use. This study pays attention to the total grade from the scale in determining the problematic Internet use.

\section{3. 3. Meaning in life questionnaire}

This scale was developed by Steger et al. (2006) and adopted to Turkish by Demirbaş (2010). The scale consisting of 10 items is 7 point likert-type. Meaning in Life Scale includes two sub-dimensions as to be "presence of meaning" (e.g. "I understand my life's meaning") and "search for meaning" (e.g. "I am looking for something that makes my life feel meaningful") and no total point is obtained for scale. During the realiability studies of Turkish version, internal consistency values was found to be .87 for presence of the meaning in life and .88 for dimension of search for meaning in life. In principal component analysis conducted for validity study, it was observed that the scale maintained the two dimensional structure in its origin. Relevant to the consistency of the two factor model, GFI, NFI, and CFI values were calculated over .95.

\section{3. 4. General Self-efficacy scale}

General Self-Efficacy Scale was developed by Sherer et al. (1982). Validity and reliability studies for the Turkish sample of the scale was performed by Yildırm and Ilhan (2010). The 5point Likert-type scale consists of 17 items 11 of which is negative reverse-coding (e.g. "I give up on things before completing them") and 6 is positive (e.g. "When i make plans, I am certain I can make them work"). Increase of the scores from the scale indicates the increase in general selfefficacy belief. Cronbach alpha value showing the internal consistency of the scale in reliability 
Aydın, B. (2017). Resorting to Internet: A look at university students' problematic Internet use through meaning in life, self-efficacy and self-esteem. Journal of Human Sciences, 14(2), 1938-1950. doi:10.14687/jhs.v14i2.4480

study of Turkish version was calculated as .80. The correlation between two applications in examining the reliability of the test-retest was found to be .69. In validity study of the General SelfEfficacy Scale Turkish version, a three factor structure was obtained as "starting", "not giving up", and "sustaining efforts" which explain the $41.47 \%$ of the total variance. Additionally, the correlations with Locus of Control Scale, Learned Resourcefulness Scale, Beck Depression Inventory and Coopersmith Self-Esteem Inventorys were calculated as .-30, .57, .-49 and .48, respectively.

\section{3. 5. Rosenberg self-esteem scale}

The scale was developed by Rosenberg (1965) was adapted to Turkish by Çuhadaroğlu (1986). The whole of the scale consists of 12 sub-categories and 63 items. One of these categories is Self-Esteem sub-category constituting 10 items and these 10 items of the relevant sub-category were used in measuring the self-esteem in this study. Self-Esteem sub-category consists of 5 positive ("I take a positive attitude toward myself") and 5 negative reverse-coding items ("All in all, i'm inclined to feel that i'm failure") and is 4-points Likert-type. Increasing scores indicate the increase in the level of self-esteem. Psychiatric interviews were made to test the validity of the selfesteem category in Turkish adaptation process of the scale. Upon evaluation with such interviews, self-esteems of the students were grouped into "high", "medium", and low" with regards to their views on themselves. The relationships between the results from the views and application of the self-esteem scale were calculated and validity rate was found to be .71 . Test-retest validity coefficient of the scale was found to be .75. And in the present study, Cronbach alpha value showing the internal consistency of the scale was found as .74 .

\section{4. Data analysis}

Data were analized via SPSS 15.0 version. Descriptive statistics were benefited in obtaining the findings relevant to the sociodemographic characteristics of the participants. The relationship of problematic Internet use with meaning in life, self-efficacy and self-esteem was determined by Pearson product moments correlation coefficient. Multiple linear regression analysis was used in determining the roles of meaning in life, self-efficacy, and self-esteem in predicting the problematic Internet use.

\section{Results}

\section{1. Relationships between variables}

Based on the Pearson correlation results (as seen in Table 1) where the relationship between the variables is examined, problematic Internet use is significantly and positively $(r=.21, p<.01)$ correlated to the search for meaning in life. On the other hand, there is a significant and negative correlation between problematic Internet use and presence of meaning in life $(r=-.26, p<.01)$, selfefficacy $(\mathrm{r}=-.36, \mathrm{p}<.01)$, and self-esteem $(\mathrm{r}=-.30, \mathrm{p}<.01)$. Based on such findings, the more search for meaning in life increases, the more level of problematic Internet use increases. The more perception of meaning in life, self-efficacy and self-esteem increase, the more problematic Internet use decreases. 
Aydin, B. (2017). Resorting to Internet: A look at university students' problematic Internet use through meaning in life, self-efficacy and self-esteem. Journal of Human Sciences, 14(2), 1938-1950. doi:10.14687/jhs.v14i2.4480

Table 1. Relationships between problematic Internet use, meaning in life, self-efficacy and self-esteem

\begin{tabular}{|c|c|c|c|c|c|}
\hline & 1 & 2 & 3 & 4 & 5 \\
\hline $\begin{array}{l}\text { 1. Problematic } \\
\text { Internet use }\end{array}$ & 1 & & & & \\
\hline $\begin{array}{l}\text { 2. Search for } \\
\text { meaning in life }\end{array}$ & $.21 * *$ & 1 & & & \\
\hline $\begin{array}{l}\text { 3. Presence of } \\
\text { meaning in life }\end{array}$ & $-.26 * *$ & $-.18^{* *}$ & 1 & & \\
\hline 4. Self-efficacy & $-.36 * *$ & $-.14 * *$ & $.37 * *$ & 1 & \\
\hline 5. Self-esteem & $-.30 * *$ & $-.24 * *$ & $.40^{* *}$ & $.52^{* *}$ & \\
\hline Mean & 65.88 & 22.65 & 27.66 & 63.04 & 31.31 \\
\hline $\begin{array}{l}\text { Standard } \\
\text { Deviation }\end{array}$ & 23.05 & 7.13 & 5.51 & 10.18 & 5.02 \\
\hline
\end{tabular}

\section{2. Prediction of problematic Internet use}

The results of multiple linear regression analysis, as can be seen in Table 2, show that the established regression model is significant and search for meaning in life, presence of meaning in life, self-efficacy and self-esteem explain $16 \%$ of the total variance in problematic Internet use. $\left(\mathrm{F}_{(4,405)}=21.33, \mathrm{p}<.01\right)$. Unique contributions of search for meaning in life $(\beta=.13, \mathrm{p}<.01)$, presence of meaning in life $(\beta=-.10, p<.05)$, and self-efficacy $(\beta=.-25, p<.01)$ was found to be significant. However, self-esteem $(\beta=-.08, \mathrm{p}>.05)$ does not have a significant predictive role.

Table 2. Results of multiple linear regression analysis in prediction of problematic Internet use

\begin{tabular}{|c|c|c|c|c|c|c|c|c|}
\hline Variable & B & $\beta$ & $\mathbf{t}$ & $\mathrm{p}$ & $\mathbf{R}$ & $\mathbf{R}^{2}$ & $\Delta \mathbf{R}^{2}$ & $\mathbf{F}$ \\
\hline Constant & 117.32 & - & 12.42 & .00 & & & & \\
\hline Search for & .43 & .13 & 2.88 & $.00^{* *}$ & & & & \\
\hline $\begin{array}{c}\text { meaning in } \\
\text { life }\end{array}$ & & & & & .41 & .17 & .16 & 21.33 \\
\hline $\begin{array}{l}\text { Presence of } \\
\text { meaning in } \\
\text { life }\end{array}$ & -.43 & -.10 & -2.02 & $.04 *$ & & & & \\
\hline Self-efficacy & -.58 & -.25 & -4.80 & $.00 * *$ & & & & \\
\hline Self-esteem & -.40 & -.08 & -1.57 & .11 & & & & \\
\hline
\end{tabular}

\section{Discussion}

The results of the present study indicate that search for meaning in life is positively and significantly correlated to the problematic Internet use (H1). Presence of meaning in life (H2), selfefficacy (H3) and self-esteem $(\mathbf{H} 4)$ are negatively and significantly correlated to problematic Internet use. Furthermore, search for meaning in life, presence of meaning in life and self-efficacy were found to be significant predictors of the problematic Internet use, while the predictive role of self-esteem is not significant. In other words, $5^{\text {th }}$ Hypothesis $(\mathbf{H} 5)$ was partly verified.

Meaning in life is considered to be one of the main motivations for a happy, productive, and healthy life in psychology literature. Individuals perceiving their lives meaningful feel better psychologically and physically (Reopke et al., 2014; Steger et al., 2009; Steger et al., 2015). On the other hand, psychopathologies such as anxiety, depression are more common among those feeling 
Aydın, B. (2017). Resorting to Internet: A look at university students' problematic Internet use through meaning in life, self-efficacy and self-esteem. Journal of Human Sciences, 14(2), 1938-1950. doi:10.14687/jhs.v14i2.4480

inadequacies or searching for meaning (Steger et al., 2009). Furthermore, these individuals displays more health risking behaviors than those perceiving their lives meaningful and they are more inclined to addictions (Marco et al., 2015; Thege et al., 2013). In other words, individuals make efforts to compensate such meaning inadequacies with maladaptive ways. The fact that the search for meaning is positively correlated to problematic Internet use, meaning of life is negatively correlated, and both of them were found to be significant predictors signifies us that the perceived inadequacy of meaning is being tried to be compensated by maladaptive Internet use. In studies orienting on the source of meaning in life; relationships, success-productivity, personal development, autonomy/independence, pleasure/having a good time are considered common factors for a meaningful life (Bar-Tur, Savaya \& Prager, 2001; Reker, 2000; Schnell, 2009). The researches on the needs to use the Internet or specific application of Internet indicate that individuals meet their needs commonly like establishing relationships-socializing, expressing themselves more freely, spending-enjoying time, taking information, aesthetic experience through the use of Internet (Papacharissi \& Rubin, 2000; Park, Kee \& Valenzuela, 2009; Song, LaRose, Eastin \& Lin, 2004). Also, for those who use Internet for mainly socializing or creating a new social environment, discovering creative elements, looking for information, and sustaining relationships, the risk of Internet addiction is reported to be higher (Song et al., 2004). Depending on the severity of the individual's needs or their level to satisfy, the inclination of the individual to search for this inadequacy in a different environment gets higher (Suler, 1999). Perception of meaning in life has a critical role in understanding the life worthy to live (Frankl, 2006). It is therefore possible that the inadequacy perceived for meaning will be compensated in another way. Since the Internet is an easy-to-reach, colorful, less threatening platform for freedoms and it draws interest and attention, it can be considered as an appropriate environment for searching for meaning. Any person in real life may not consider himself sufficiently productive, free, or satisfied from spending the time, obtaining or sharing information. This person may prefer to meet his/her relationship, information, entertainment, freedom, success-productivity needs related to the meaning via Internet, anonymously or not, by means of sharing text, photo or image freely, creating original contents or taking likes by sharing such contents, expanding his social network or establishing a new network, finding and exchanging meaningful information with individuals with the same needs as him, and discovering unique applications. In this case, it is likely to spend more time on the Internet and have a more need to go online as well as the emergence of problematic Internet use. And, because those perceiving their lives as meaningful do not need such a compensation, they are expected use the Internet functionally and reasonably. The negative relationship between the presence of meaning and problematic Internet use can be explained in this way.

The fact that self-efficacy was negatively correlated to problematic Internet use and found to be a significant predictor of the problematic Internet use supports the idea that individuals with low self-efficacy belief are more inclined to addictions (Marlatt et al., 1999) and they may try to overcome the inadequacies perceived in real life by mean of Internet applications (KardefeltWinther, 2014a; Young et al., 2011). Self-efficacy belief is one of the most important variables affecting the behaviors the person can choose and his control on such behaviors (Bandura, 1999a:2). The individuals with low self-efficacy beliefs have problems in following their behaviors and determining under which cognitive and emotional factors they occurred, having control over their behaviors, determining different ways to deal with the hard times, and sustaining their efforts to deal with and prefer less effective and inconsistent methods to regulate themselves (Bandura, 1999b:214). One of such ways may be the maladaptive use of Internet; individuals with low selfefficacy may be spending time longer and more frequently than those with high self-efficacy levels and might have problems in controlling the use. An individual with a low self-efficacy can turn towards Internet as a means, which is easy-to-reach, interesting, away from the pressures and stressful conditions to deal with the inadequacy and problems perceived in real life with regards to family, social, academic or occupational aspects. He can believe that he better expresses himself, is more successful and effective in social networks, gaming, entertainment, friendship and flirting sites 
Aydın, B. (2017). Resorting to Internet: A look at university students' problematic Internet use through meaning in life, self-efficacy and self-esteem. Journal of Human Sciences, 14(2), 1938-1950. doi:10.14687/jhs.v14i2.4480

away from the problems and stresses existing in daily life and face to face communication and he may feel more efficient on such sites. And because he feels this situation means regulating himself, the risk of problematic Internet use emerges due to the need to go online more frequent and longer hours will increase. Aside from the high likelihood that the individuals with low self-efficacy may take shelter under Internet as a strategy of regulating themselves, it also seems possible that they will fail to limit their hours of Internet use in time. Low level of self-efficacy already available may cause the individual to feel weak in controlling his overuse of Internet and dealing with that problem or sustaining his efforts to limit the usage. This condition brings another explanation to the determinant feature of the self-efficacy belief on problematic Internet use.

The other variable found to be negatively and significantly correlated to the problematic Internet use is the self-esteem. Self-esteem is considered to be positively correlated to the mental health in and adaptive behaviors in different life domains and to have a determining effect on such variables (Dumont \& Provost, 1999; Judge \& Bono, 2001; Paradise \& Kernis, 2002). Low selfesteem, on the other hand, is a risk factor for psychopathologies such as depression and anxiety and maladaptive behaviors (Donnellan et al., 2005; Sowislo \& Orth, 2013). Furthermore, individuals with low self-esteem try to feel better about themselves through gambling, compulsive shopping and drug use and so seem more inclined to addictions (Hanley \& Wilhelm, 1992; Peterson et al., 2010; Volberg et al., 1997). Researches similarly indicate that one of the needs the individuals from different age groups try to meet through the use of Internet is "feeling better about himself" (Lee et al., 2011; Urista, Dong \& Day, 2009; Valkenburg et al., 2009). It is even reported that those using Internet for such reasons spend more time online and become under risk for addiction (Mehdizadeh, 2010). In real life, the feedback obtained by the individual from others during his/her interaction affects the self-esteem and while the positive feedback strengthens the self-esteem, negative ones make it go down. And the individual sometimes relies on maladaptive means to acceptance which is missing in this interaction (Hewitt, 2002). One of such maladaptive means can be stated as the overuse of Internet. The fact that Internet is a platform which provides less stress compared to daily interactions and allows the individual to communicate with others anonymously where necessary and to present himself whatever he wants to be to gain acceptance that he couldn't take on daily life (Young, 2004), may express the reason behind that the individuals with low selfesteem go online more frequently and longer hours to compensate their inadequacies. The young individual who perceives that he is not accepted enough during his real life experiences and therefore feeling himself worthless may prefer to feel himself worthy by means of the likes he gains through the profile and sharing on Internet. Furthermore, with his real profile or another way, he may present himself as "how he wants to be" and thus feel himself more valuable. Because he indexed his self-worth to Internet related applications substantially, it seems likely that he will feel needy to stay longer hours on Internet and suffer from lack of Internet when he is not online for a long time.

\section{Conclusion and Recommendations}

The findings concluded from this research indicate that meaning in life, self-efficacy, and selfesteem have important roles with regards to the problematic Internet use by university students. The process of configuring the ideological, moral, occupational, and sexual identity which started at adolescence has not ended yet for university students. Additionally, they live in a period which comes after adolescence and during which significant close relationships with the opposite sex become important. It is deemed important for both periods that students should feel a satisfaction regarding the identity orientations, course and importance of their lives and perceive themselves adequate for identity achievement and close relationships and consider themselves worthy not to experience alienation in either friend relationships or close relationships. In literature and discussion part of this research, as also supported by the relevant research findings, one of the means to deal with perceived inadequacies and compensate thereof is considered as Internet use and this causes the risk of problematic use. In counseling interviews regarding the treatment of problematic 
Aydın, B. (2017). Resorting to Internet: A look at university students' problematic Internet use through meaning in life, self-efficacy and self-esteem. Journal of Human Sciences, 14(2), 1938-1950. doi:10.14687/jhs.v14i2.4480

Internet use, helping the youth in raising awareness on why they actually use the Internet for should be considered as a principal intervention. The young individual may express that he goes online for significant activities, he feels more interactive with people, enjoys the life better on Internet, takes better feedbacks from people on being successful and a worthy person. It will be useful to determine the inadequacy behind this need based on the statements provided during the interview, and to meet such inadequacies with adaptive actions in real life. In this regard, guiding the young, searching for the real life opportunities together with the young to help him meet his needs such as socialization, close relationship, productivity-creativity, performing meaningful activities, obtaining significant information, looking for identity alternatives may ensure that the focus point may be turned into real life. Furthermore, helping the young in evaluating his efficiency and worthiness objectively, questioning his self-defeating beliefs thereof, and helping in developing a more realistic and positive self concept through positive comparisons in daily life activities stated above seem important for the individual. On the other hand, Internet should not be imposed as a pattern which causes addiction and ruins the mental health. As long as Internet, during the counseling interviews, is considered as "only one of" the sources to apply for communication, national and global awareness, supporting the current relationships, familiarizing with new cultures and solving the problems.

In this research, meaning in life, self-efficacy and self-esteem were approached as an antecedent of problematic Internet use. On the other hand, spending time more than required on Internet, being isolated from the real life, failure to restrict the use may also cause reduction of perceived meaning in life, efficacy and worthiness perceptions. This condition which can be accepted as limitation for this research can be expressed by longitudinal research designs in similar researches. Another limitation of current research is the collection of data from a single faculty. In similar researches with university students focusing on meaning in life, self-efficacy, self-esteem, and problematic Internet use, collecting data from different faculties can render such studies more significant. As the data collection tools used in this study based on self-report, the possibility of being affected from social desirability may also be specified as a limitation.

\section{References}

Aboujaoude, E., Koran, L. M., Gamel, N., Large, M. D., \& Serpe, R. T. (2006). Potential markers for problematic Internet use: A telephone survey of 2,513 adults. CNS Spectrums, 11(10), 750-755.

Armstrong, L., Phillips, J. G., \& Saling, L. L. (2000). Potential determinants of heavier Internet usage. International Journal of Human-Computer Studies, 53(4), 537-550.

Bandura, A. (1999a). Excercise of personal and collective efficacy in changing societies. In A.

Bandura (Ed.), Self-efficacy in changing societies (pp. 1-46). Cambridge: Cambridge University Press.

Bandura, A.(1999b). A sociocognitive analysis of substance use: An agentic perspective. Psychological Science, 1(3), 214-217.

Bar-Tur, L., Savaya, R., \& Prager, E. (2001). Sources of meaning in life for young and old Israeli Jews and Arabs. Journal of Aging Studies, 15(3), 253-269.

Cao, H., Sun, Y., Wan, Y., Hao, J., \& Tao, F. (2011). Problematic Internet use in Chinese adolescents and its relation to psychosomatic symptoms and life satisfaction. Retrieved February 20, 2016 from http://bmcpublichealth.biomedcentral.com/articles/10.1186/1471-2458-11-802.

Caplan, S. E. \& High, A. C. (2011). Online social interaction, psychological well-being, and problematic Internet use. In K. S. Young \& C. N. De Abreu (Eds.) Internet addiction: A bandbook and guide to evaluation and treatment (pp. 35-55). New Jersey: John Wiley \& Sons.

Ceyhan, E., Ceyhan, A. A., \& Gürcan, A. (2007). Problemli internet kullanımı ölçeğinin geçerlik ve güvenirlik çalışmaları. [The validity and reliability of the problematic Internet usage scale]. Kuram ve Uygulamada Eğitim Bilimleri. [Educational Sciences: Theory \& Practice], 7(1), 387-416.

Dalbudak, E., Evren, C., Aldemir, S., \& Evren, B. (2014). The severity of Internet addiction risk and its relationship with the severity of borderline personality features, childhood traumas, dissociative 
Aydin, B. (2017). Resorting to Internet: A look at university students' problematic Internet use through meaning in life, self-efficacy and self-esteem. Journal of Human Sciences, 14(2), 1938-1950. doi:10.14687/jhs.v14i2.4480

experiences, depression and anxiety symptoms among Turkish university students. Psychiatry Research, 219(3), 577-582.

Çuhadaroğlu, F. (1986). Adolesanlarda benlik saygisı [Self-esteem in adolescents]. Unpublished medical speciality thesis. Hacettepe University Faculty of Medicine, Department of Psychiatry, Ankara.

Davis, R. A. (2001). A cognitive-behavioral model of pathological Internet use. Computers in Human Behavior, 17(2), 187-195.

Debats, D. L. (1996). Meaning in life: Clinical relevance and predictive power. British Journal of Clinical Psychology, 35(4), 503-516.

Demirbaş, N. (2010). Yaşamda anlam ve yulmą̧lke [Meaning in life and resilience]. Unpublished master thesis. Hacettepe University, Graduate School of Social Sciences, Ankara.

Donnellan, M. B., Trzesniewski, K. H., Robins, R. W., Moffitt, T. E., \& Caspi, A. (2005). Low self-esteem is related to aggression, antisocial behavior, and delinquency. Psychological Science, 16(4), 328-335.

Dumont, M., \& Provost, M. A. (1999). Resilience in adolescents: Protective role of social support, coping strategies, self-esteem, and social activities on experience of stress and depression. Journal of Youth and Adolescence, 28(3), 343-363.

Frankl, V. E. (2006). Man's search for meaning. Boston: Beacon Press.

Goldberg, I. (1996). Internet addiction disorder. Retrieved February 13, 2016 from http://www.physics.wisc.edu/ shalizi/internet addiction criteria.html

Hanley, A., \& Wilhelm, M. S. (1992). Compulsive buying: An exploration into self-esteem and money attitudes. Journal of Economic Psychology, 13(1), 5-18.

Hardie, E., \& Tee, M. Y. (2007). Excessive Internet use: the role of personality, loneliness and social support networks in Internet addiction. Australian Journal of Emerging Technologies \& Society, 5(1), 34-47.

Hewitt, J. P. (2002). The social construction of self-esteem. In C. R. Snyder \& S. J. Lopez (Eds.), Oxford Handbook of Positive Psychology (pp. 135-148). New York: Oxford University Press.

Huan, V. S., Ang, R. P., Chong, W. H., \& Chye, S. (2014). The impact of shyness on problematic Internet use: The role of loneliness. The Journal of Psychology, 148(6), 699-715.

Huang, R. L., Lu, Z., Liu, J. J., You, Y. M., Pan, Z. Q., Wei, Z., ... \& Wang, Z. Z. (2009). Features and predictors of problematic Internet use in Chinese college students. Behaviour \& Information Technology, 28(5), 485-490.

Internet Live Stats (2016). Number of Internet Users. Retrieved February 13, 2016 from Internet Live Stats Website, http://www.internetlivestats.com/internet-users/.

Internet Society (2012). Global Internet User Survey 2012. Retrieved April 22, 2015, from Internet Society Website, https://www.internetsociety.org/sites/default/files/rep-GIUS2012global-201211-en.pdf.

Internet World Stats (2015). Top 20 Internet Countries. Retrieved April 20, 2015 from Internet World Stats Website, http://www.internetworldstats.com/top20.htm.

İskender, M., \& Akin, A. (2010). Social self-efficacy, academic locus of control, and Internet addiction. Computers \& Education, 54(4), 1101-1106.

Johansson, A., \& Götestam, K. G. (2004). Internet addiction: characteristics of a questionnaire and prevalence in Norwegian youth (12-18 years). Scandinavian Journal of Psychology, 45(3), 223-229.

Judge, T. A., \& Bono, J. E. (2001). Relationship of core self-evaluations traits-self-esteem, generalized selfefficacy, locus of control, and emotional stability—with job satisfaction and job performance: A meta-analysis. Journal of Applied Psychology, 86(1), 80-92.

Kandell, J. J. (1998). Internet addiction on campus: The vulnerability of college students. CyberPsychology \& Behavior, 1(1), 11-17.

Kardefelt-Winther, D. (2014a). A conceptual and methodological critique of Internet addiction research: Towards a model of compensatory internet use. Computers in Human Behavior, 31, 351-354.

Kardefelt-Winther, D. (2014b). Problematizing excessive online gaming and its psychological predictors. Computers in Human Behavior, 31, 118-122.

Kim, H. K., \& Davis, K. E. (2009). Toward a comprehensive theory of problematic Internet use: Evaluating the role of self-esteem, anxiety, flow, and the self-rated importance of Internet activities. Computers in Human Behavior, 25(2), 490-500.

Ko, C. H., Yen, J. Y., Chen, C. C., Chen, S. H., Wu, K. \& Yen, C.F. (2006). Tridimensional personality of adolescents with Internet addiction and substance use experience. Canadian Journal of Psychiatry, 51(14), 887-894. 
Aydin, B. (2017). Resorting to Internet: A look at university students' problematic Internet use through meaning in life, self-efficacy and self-esteem. Journal of Human Sciences, 14(2), 1938-1950. doi:10.14687/jhs.v14i2.4480

Lam, L. T., Peng, Z. W., Mai, J. C., \& Jing, J. (2009). Factors associated with Internet addiction among adolescents. CyberPsychology \& Behavior, 12(5), 551-555.

Li, D., Liau, A., \& Khoo, A. (2011). Examining the influence of actual-ideal self-discrepancies, depression, and escapism, on pathological gaming among massively multiplayer online adolescent gamers. Cyberpsychology, Behavior \& Social Networking 14(9), 535-539.

Liu, T. C., Desai, R. A., Krishnan-Sarin, S., Cavallo, D. A., \& Potenza, M. N. (2011). Problematic Internet use and health in adolescents: data from a high school survey in Connecticut. The Journal of Clinical Psychiatry, 72(6), 1-478.

Luszczynska, A., Gutiérrez-Doña, B., \& Schwarzer, R. (2005). General self-efficacy in various domains of human functioning: Evidence from five countries. International Journal of Psychology, 40(2), 80-89.

Mehdizadeh, S. (2010). Self-presentation 2.0: Narcissism and self-esteem on Facebook. Cyberpsychology, Behavior \& Social Networking, 13(4), 357-364.

Marco, J. H., Garcia-Alandete, J., Pérez, S., Guillen, V., Jorquera, M., Espallargas, P., \& Botella, C. (2015). Meaning in life and non-suicidal self-injury: A follow-up study with participants with Borderline Personality Disorder. Psychiatry Research, 230(2), 561-566.

Marlatt, G. A., Baer, J. S. \& Quigley, L. A. (1999). Self-efficacy and addictive behavior. In A. Bandura (Ed.), Self-efficacy in changing societies (pp. 289-317). Cambridge: Cambridge University Press.

Nicholson, T., Higgins, W., Turner, P., James, S., Stickle, F., \& Pruitt, T. (1994). The relation between meaning in life and the occurrence of drug abuse: A retrospective study. Psychology of Addictive Behaviors, 8(1), 24-28.

Niemz, K., Griffiths, M., \& Banyard, P. (2005). Prevalence of pathological Internet use among university students and correlations with self-esteem, the General Health Questionnaire (GHQ), and disinhibition. CyberPsychology \& Behavior, 8(6), 562-570.

Odac1, H. (2011). Academic self-efficacy and academic procrastination as predictors of problematic Internet use in university students. Computers \& Education, 57(1), 1109-1113.

Papacharissi, Z., \& Rubin, A. M. (2000). Predictors of Internet use. Journal of Broadcasting \& Electronic Media, 44(2), 175-196.

Paradise, A. W., \& Kernis, M. H. (2002). Self-esteem and psychological well-being: Implications of fragile self-esteem. Journal of Social and Clinical Psychology, 21(4), 345-361.

Park, N., Kee, K. F., \& Valenzuela, S. (2009). Being immersed in social networking environment: Facebook groups, uses and gratifications, and social outcomes. CyberPsychology \& Behavior, 12(6), 729-733.

Peterson, C. H., Buser, T. J., \& Westburg, N. G. (2010). Effects of familial attachment, social support, involvement, and self-esteem on youth substance use and sexual risk taking. The Family Journal, 16, 18.

Reker, G. T. (2000). Theoretical perspective, dimensions and measurement of existential meaning. In G. T. Reker \& K. Chamberlain (Eds.) Exploring existential meaning: Optimizing buman development across the life span (pp. 39-55). Thousands Oaks: Sage Publications.

Roepke, A. M., Jayawickreme, E., \& Riffle, O. M. (2014). Meaning and health: A systematic review. Applied Research in Quality of Life, 9 (4), 1055-1079.

Rosenberg, M. (1965). Society and the adolescent self-image. Princeton, NJ: Princeton University Press.

Rosenberg, M., Schooler, C., Schoenbach, C., \& Rosenberg, F. (1995). Global self-esteem and specific selfesteem: Different concepts, different outcomes. American Sociological Review, 60 (1) 141-156.

Schnell, T. (2009). The Sources of Meaning and Meaning in Life Questionnaire (SoMe): Relations to demographics and well-being. The Journal of Positive Psychology, 4(6), 483-499.

Sherer, M., Maddux, J. E., Mercandante, B., Prentice-Dunn, S., Jacobs, B., \& Rogers, R. W. (1982). The selfefficacy scale: Construction and validation. Psychological Reports, 51(2), 663-671.

Smahel, D., Blinka, L., \& Ledabyl, O. (2008). Playing MMORPGs: Connections between addiction and identifying with a character. CyberPsychology \& Behavior, 11(6), 715-718.

Song, I., Larose, R., Eastin, M. S., \& Lin, C. A. (2004). Internet gratifications and Internet addiction: On the uses and abuses of new media. CyberPsychology \& Behavior, 7(4), 384-394.

Sowislo, J. F., \& Orth, U. (2013). Does low self-esteem predict depression and anxiety? A meta-analysis of longitudinal studies. Psychological Bulletin, 139(1), 213-240.

Steger, M. F., Frazier, P., Oishi, S., \& Kaler, M. (2006). The meaning in life questionnaire: Assessing the presence of and search for meaning in life. Journal of Counseling Psychology, 53(1), 80-93. 
Aydın, B. (2017). Resorting to Internet: A look at university students' problematic Internet use through meaning in life, self-efficacy and self-esteem. Journal of Human Sciences, 14(2), 1938-1950. doi:10.14687/jhs.v14i2.4480

Steger, M. F., Kashdan, T. B., Sullivan, B. A., \& Lorentz, D. (2008). Understanding the search for meaning in life: Personality, cognitive style, and the dynamic between seeking and experiencing meaning. Journal of Personality, 76(2), 199-228.

Steger, M. F., Mann, J. R., Michels, P., \& Cooper, T. C. (2009). Meaning in life, anxiety, depression, and general health among smoking cessation patients. Journal of Psychosomatic Research, 67(4), 353-358.

Steger, M. F., Fitch-Martin, A. R., Donnelly, J., \& Rickard, K. M. (2015). Meaning in life and health: Proactive health orientation links meaning in life to health variables among American undergraduates. Journal of Happiness Studies, 16(3), 583-597.

Suler, J. R. (1999). To get what you need: healthy and pathological Internet use. CyberPsychology \& Behavior, 2(5), 385-393.

Şenormanc1, Ö., Şenormanc1, G., Güçlü, O., \& Konkan, R. (2014). Attachment and family functioning in patients with Internet addiction. General Hospital Psychiatry, 36(2), 203-207.

Thege, B. K., Urbán, R., \& Kopp, M. S. (2013). Four-year prospective evaluation of the relationship between meaning in life and smoking status.Retrieved March 12, 2016 from bttp:// substanceabusepolicy.biomedcentral.com/articles/10.1186/1747-597X-8-8.

Urista, M. A., Dong, Q., \& Day, K. D. (2009). Explaining why young adults use MySpace and Facebook through uses and gratifications theory. Human Communication, 12(2), 215-229.

Valkenburg, P. M., Peter, J., \& Schouten, A. P. (2006). Friend networking sites and their relationship to adolescents' well-being and social self-esteem. CyberPsychology \& Behavior, 9(5), 584-590.

Volberg, R. A., Reitzes, D. C., \& Boles, J. (1997). Exploring the links between gambling, problem gambling, and self-esteem. Deviant Behavior, 18(4), 321-342.

Weisberg, J. L., \& Porter, J. E. (1994). Purpose in life and outcome of treatment for alcohol dependence. British Journal of Clinical Psychology, 33, 49-63.

Whang, L. S. M., Lee, S., \& Chang, G. (2003). Internet over-users' psychological profiles: A behavior sampling analysis on internet addiction. CyberPsychology \& Behavior, 6(2), 143-150.

Widyanto, L., \& Griffiths, M. (2006). 'Internet addiction': a critical review. International Journal of Mental Health and Addiction, 4(1), 31-51.

World Medical Assosication (2013). Declaration of Helsinki-Ethical principles for medical research involving human subjects. Retrieved February 20, 2016 from World Medical Assosication Website, http://www.wma.net/en/30publications/10policies/b3/index.html.

Yen, J. Y., Ko, C. H., Yen, C. F., Chen, C. S., \& Chen, C. C. (2009). The association between harmful alcohol use and Internet addiction among college students: comparison of personality. Psychiatry and Clinical Neurosciences, 63(2), 218-224.

Yıldırım, F., \& İlhan, İ. Ö. (2010). Genel öz yeterlilik ölçeği Türkçe formunun geçerlilik ve güvenilirlik çalışması [Validity and reliability study of the Turkish form of the General Self-efficacy Scale] Türk Psikiyatri Dergisi [Turkish Journal of Psychiatry], 21(4), 301-308.

Young, K. S. (1996). Psychology of computer use: XL. Addictive use of the Internet: a case that breaks the stereotype. Psychological Reports, 79(3), 899-902.

Young, K. S., \& Rogers, R. C. (1998). The relationship between depression and Internet addiction. CyberPsychology \& Behavior, 1(1), 25-28.

Young, K. S. (2004). Internet addiction a new clinical phenomenon and its consequences. American Behavioral Scientist, 48(4), 402-415.

Young, K. S. , Yue, X. D. \& Ying, L. (2011). Prevalance estimates and etiologic models of Internet addiction. In K. S. Young \& C. N. De Abreu (Eds.) Internet addiction: A bandbook and guide to evaluation and treatment (pp. 3-19). New Jersey: John Wiley \& Sons. 